Check for updates

Cite this: Nanoscale, 2020, 12, 20165

Received 31st July 2020,

Accepted 24th September 2020

DOI: $10.1039 /$ d0nr05659f

rsc.li/nanoscale

\section{Carbon supported noble metal nanoparticles as efficient catalysts for electrochemical water splitting $\dagger$}

 \\ Francesco Paolucci ${ }^{a}$ and Alain Pénicaud (D) *b,c
}

Due to an increasing requirement of clean and sustainable hydrogen energy economy, it is significant to develop new highly effective catalysts for electrochemical water splitting. In alkaline electrolyte, Platinum (Pt) shows a much slower hydrogen evolution reaction (HER) kinetics relative to acidic condition. Here, we show a versatile synthetic approach for combining different noble metals, such as Rhodium (Rh), RhPt and Pt nanoparticles, with carbon forming noble metal nanoparticles/nanocarbon composites, denoted as $\mathrm{Rh}(\mathrm{nP}) / \mathrm{nC}, \mathrm{RhPt}(\mathrm{nP}) / \mathrm{nC}$ and $\mathrm{Pt}(\mathrm{nP}) / \mathrm{nC}$, respectively. It was found that in alkaline media these composites exhibited higher performance for the HER than the commercial Pt/C. In particular, $\mathrm{Rh}(\mathrm{nP}) / \mathrm{nC}$ displayed a small overpotential of $44 \mathrm{mV}$ at a current density of $5 \mathrm{~mA} \mathrm{~cm} \mathrm{~cm}^{-2}$ and a low Tafel slope of $50 \mathrm{mV}$ $\operatorname{dec}^{-1}$. Meanwhile, it also showed a comparable activity for the oxygen evolution reaction (OER) to the benchmarking catalyst $\mathrm{RuO}_{2}$. The superior HER and OER performance benefits from the very small size of nanoparticles and synergy between carbon support and nanoparticles.

\section{Introduction}

Hydrogen has been considered as an ideal energy carrier due to its high energy density and potentially environmentally friendly production by the solar assisted splitting of water. ${ }^{1}$ Water electrolysis in alkaline media, which includes the hydrogen evolution reaction (HER) at the cathode and the oxygen evolution reaction (OER) at the anode, is an efficient approach to generate large volumes of hydrogen. ${ }^{2-4}$ The efficiency of electrocatalytic water splitting is directly related to the activity

\footnotetext{
${ }^{a}$ Department of Chemistry "G. Ciamician”, University of Bologna, via Selmi 2, 40126 Bologna, Italy

${ }^{b}$ CNRS, Centre de Recherche Paul Pascal (CRPP), UMR 5031, F-33600 Pessac, France. E-mail: alain.penicaud@crpp.cnrs.fr

${ }^{c}$ Université Bordeaux, CRPP, UMR 5031, F-33600 Pessac, France

$\dagger$ Electronic supplementary information (ESI) available: Scheme S1, Tables S1 and Fig. S1-S13. See DOI: 10.1039/d0nr05659f
}

of the respective catalysts used in both electrochemical half cells. Noble metal-based materials, such as $\mathrm{Pt} / \mathrm{C}$ and $\mathrm{IrO}_{2}$ (or $\mathrm{RuO}_{2}$ ), are used as benchmarking catalysts for the HER and OER, respectively. ${ }^{5}$ However, the catalytic activity of Pt for the HER in alkaline electrolyte is about two orders of magnitude lower than in acidic media. ${ }^{6}$ The OER, which ideally is a fourelectron transfer process involving multiple intermediates, suffers from issues, such as high overpotential, product distribution, and activity loss over time. ${ }^{7}$ Therefore, it still remains a challenge to generate catalysts (beyond $\mathrm{Pt}$, Ir and $\mathrm{Ru}$ ) for both the HER and OER that can exhibit selectivity, keep stable over time and can be produced by low cost methods in large quantities.

In order to reduce the cost for water electrolysis, substantial effort has been made to develop catalysts like non-noble metals and non-metallic materials. ${ }^{8}$ However, their catalytic performance largely falls behind noble metal catalysts. ${ }^{9}$ As a well-known noble metal, rhodium (Rh) has shown high catalytic property towards a couple of reactions including $\mathrm{CO}_{2}$ reduction, $\mathrm{CO}$ oxidation, $\mathrm{N}_{2} \mathrm{O}$ decomposition etc. ${ }^{10-14}$ For example, Huang et al. reported a route to synthesize a series of Rh nanocrystals, including tetrahedron, concave tetrahedron and nanosheet, which showed efficient HER and OER activity. ${ }^{15}$ Chen et al. explored ultrathin $\mathrm{Rh}_{2} \mathrm{O}_{3}$ nanosheet assemblies and used them as OER electrocatalyst. ${ }^{16}$ However, up to now the study of Rh as noble metal in electrocatalysis still lags much behind to the its Pt counterpart.

Generally, decreasing the size of metal nanostructures can increase the ratio of surface area to volume and enhance the exposure of surface atoms. ${ }^{17}$ Chen and his coworkers have reported many excellent works on electrocatalysis by means of in situ/operando studies specially for identifying real active sites. ${ }^{18-23}$ In one of their works, a series of operando measurements, including in situ X-ray absorption spectroscopy, liquidphase transmission electron microscopy, and in situ Raman spectroscopy, were conducted to unravel in real time the structural and chemical stability of P-substituted $\mathrm{CoSe}_{2}$ electrocatalysts under both HER and OER. ${ }^{18}$ An attractive way to further 
improve the utilization of metal nanostructures is combining them with appropriate supports that possess both high electrical conductivity and high surface area. Carbon-based supports, such as carbon nanotubes and nitrogen-doped graphene, have already been employed to achieve increased surface loading and better dispersion of metal nanostructures. ${ }^{24-27}$ For instance, Guo et al. synthesized well-dispersed Rh nanocrystals on single-walled carbon nanotubes as a highly effective electrocatalyst for the HER both in acid and alkaline media. ${ }^{28}$

We have recently developed a novel synthetic approach for the preparation of carbon metal oxide/hydroxide composite materials using graphenide solutions, charge stabilized graphene layers in solution, directly as reducing agent. ${ }^{29,30}$ This approach allows to graft small and size calibrated nanoparticles randomly distributed onto the carbon frameworks by simultaneously controlling the grafting ratio and the respective size distribution. ${ }^{31,32}$ This control is achieved by the exploitation of the graphenide solution as the reduction agent as the redox process can take place only in the proximity of the carbon lattice and because the number of electrons on the carbon lattice is finite. This modular approach permits the accessibility of the catalytic centers by simultaneously maintaining the conductivity of the carbon lattice.

Herein, we utilized the graphitic nano carbon ${ }^{33,34}$ as precursor to generate firstly graphenide solution and secondly noble metal ( $\mathrm{Rh}$ and $\mathrm{Pt}$ ) nanoparticle/nanocarbon composites, $\mathrm{Rh}$ $(\mathrm{nP}) / \mathrm{nC}$ and $\mathrm{Pt}(\mathrm{nP}) / \mathrm{nC}$, by the reaction of graphenide solution with anhydrous $\mathrm{RhCl}_{3}$ or $\mathrm{PtCl}_{2}$. Considering that various combinations of metals, metal alloys, and metal oxides have been used to catalyze water splitting, ${ }^{35,36}$ we also prepared a mixed sample, $\operatorname{RhPt}(\mathrm{nP}) / \mathrm{nC}$, by the reaction of graphenide solution with a mixture of equimolar $\mathrm{RhCl}_{3}$ and $\mathrm{PtCl}_{2}$. Electrocatalytic performance of the prepared materials were investigated for the OER and HER under alkaline condition. It was found that $\mathrm{Rh}(\mathrm{nP}) / \mathrm{nC}$ exhibited excellent OER activity with a low overpotential of $333 \mathrm{mV}$ at a current density of $5 \mathrm{~mA} \mathrm{~cm}{ }^{-2}$, which is comparable to that of $\mathrm{RuO}_{2}$. Meanwhile, all the three materials showed better HER property than commercial Pt/C. In order to achieve a current density of $5 \mathrm{~mA} \mathrm{~cm}^{-2}$ for $\mathrm{Rh}(\mathrm{nP}) / \mathrm{nC}$ towards the HER, an overpotential of $44 \mathrm{mV}$ was observed and a Tafel

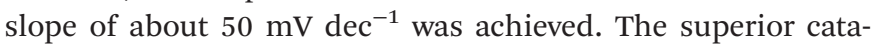
lytic performances might be traced back to the small particle size and the synergy of the two nanomaterials.

\section{Characterization}

As shown in Scheme 1, the synthesis of noble metal Rh and Pt nanoparticles/nanocarbon composites, denoted as $\mathrm{Rh}(\mathrm{nP}) / \mathrm{nC}$, $\mathrm{Pt}(\mathrm{nP}) / \mathrm{nC}$ and $\mathrm{RhPt}(\mathrm{nP}) / \mathrm{nC}$, respectively, involves the reduction of the synthetic, sustainable and almost defect free graphitic nano carbons by metallic potassium, followed by the dissolution to graphenide solution in absolute THF and reaction with equimolar amounts of anhydrous $\mathrm{PtCl}_{2}$ and/or $\mathrm{RhCl}_{3}$ salts. The achieved materials combined highly conductive carbon support with active metal nanoparticles and they were expected to display efficient performance for the OER and

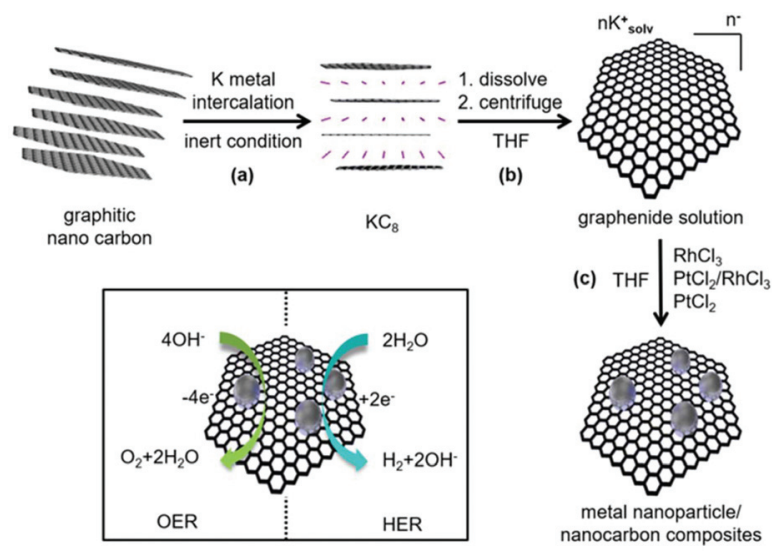

Scheme 1 Reaction scheme of the synthesis of metal nanoparticles/ nanocarbon composite materials. The respective steps are: (a) intercalation of carbon material with potassium metal (stoichiometry $\mathrm{KC}_{8}$ ); (b) dissolution and isolation of the graphenide solution in THF; (c) reaction with respective metal chlorides forming the final composites. The lower left scheme shows the combination between carbon support and nanoparticles, which may boost the exposure of active sites and the conductivity within the electrode for electrocatalysis of the OER and HER.

HER because of the synergy between carbon support and nanoparticles. Similar approaches have been utilized on transition metals (e.g. $\mathrm{Cu}, \mathrm{Fe}, \mathrm{Mn}, \mathrm{Ni}$ and $\mathrm{Co}$ ) and in all cases the formation of metal oxide/hydroxide nanoparticles grafted on the carbon sheets were observed. ${ }^{30-32}$ It was argued that the reduction generates in a first step metallic nanoparticles on the carbon framework that are oxidized during the work upstep due to the high oxophilicity of the transition metals. The electron transfer can occur only in close proximity of the carbon lattice because the charged carbon layers are the only reduction agent present. Presumably, the formation of the metallic nanoparticles is occurring due to a sequence of single electron transfer (SET) processes as argued for related reactions. $^{37}$ By XRD measurements (CuK $\alpha$, see Fig. 1a) this mechanistic interpretation can be corroborated because the obtained patterns for the $\mathrm{Pt}(\mathrm{nP}) / \mathrm{nC}$ and the $\mathrm{RhPt}(\mathrm{nP}) / \mathrm{nC}$ show
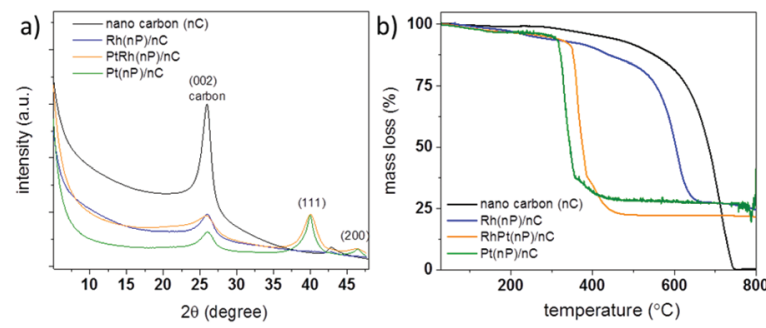

Fig. 1 (a) XRD patterns (CuK $\alpha$ ) of the three composite materials $\mathrm{Rh}(\mathrm{nP}) /$ $\mathrm{nC}$ (blue trace), $\mathrm{PtRh}(\mathrm{nP}) / \mathrm{nC}$ (orange trace), and $\mathrm{Pt}(\mathrm{nP}) / \mathrm{nC}$ (green trace) in comparison to the carbon starting material ( $\mathrm{nC}$, black trace). (b) Thermogravimetric analysis (TGA) of the three composite materials and the starting carbon material between $50-800{ }^{\circ} \mathrm{C}$ under synthetic air $\left(80 \% \mathrm{~N}_{2}, 20 \% \mathrm{O}_{2}\right)$ with a heating ramp of $10{ }^{\circ} \mathrm{C} \mathrm{min}^{-1}$. 
broad peaks at $26.1^{\circ}, 39.9^{\circ}$ and $46.5^{\circ}$ that can be attributed to the (002) pattern of the carbon material and the (111) and (200) patterns of metallic nanoparticles. In the case of the Rh (nP)/nC, only the peak at $26.1^{\circ}$ is visible. The presence of the metallic nature of nanoparticles in the samples $\mathrm{Pt}(\mathrm{nP}) / \mathrm{nC}$ and $\mathrm{RhPt}(\mathrm{nP}) / \mathrm{nC}$ have been further corroborated by XPS measurements (see Fig. S1†) as in both samples the peaks for metallic platinum are clearly visible with only a minor contribution of oxidized species. In contrast, for the $\mathrm{Rh}(\mathrm{nP}) / \mathrm{nC}$ composite, peaks for $\mathrm{Rh}(\mathrm{III})$ are visible that can be attributed to $\mathrm{Rh}_{2} \mathrm{O}_{3}$ with a minor content of metallic rhodium. This observation may be explained by the less noble character of the rhodium metal and the oxidation of the rhodium metal to the respective oxide in the work-up step.

The metal contents of the samples were determined by TGA measurements (see Fig. 1b) and remaining mass of $27.2 \%$ for the $\mathrm{Pt}(\mathrm{nP}) / \mathrm{nC}$ composite material, $26.9 \%$ for the $\mathrm{Rh}(\mathrm{nP}) / \mathrm{nC}$ and $22.1 \%$ for the $\mathrm{RhPt}(\mathrm{nP}) / \mathrm{nC}$ could be found. The notable shift of the combustion temperature of the carbon framework to significantly lower temperatures can be traced back to the accessibility and the catalytic effect of the metallic nanoparticles. This observation is in line with soot combustion research performed for optimizing diesel engines. ${ }^{38}$ The respective atomic percentage (at\%) of the noble metals in the different composites, taking into account the oxide nature for the Rh case, exhibit values between 2.1 and 2.3 at\% and was corroborated by XPS analysis. The presence of oxidized species in the $\mathrm{Rh}(\mathrm{nP}) / \mathrm{nC}$ composite was further studied by measuring XRD patterns of the residue materials after the TGA measurements and in case of the $\mathrm{Pt}(\mathrm{nP}) / \mathrm{nC}$ sample peaks for metallic Pt were observed whereas for the $\mathrm{Rh}(\mathrm{nP}) / \mathrm{nC}$ peaks that can be attributed to $\mathrm{Rh}_{2} \mathrm{O}_{3}$ have been found (see Fig. S2†). A slight shift between the XRD patterns of $\mathrm{Pt}(\mathrm{nP}) / \mathrm{nC}$ and $\mathrm{RhPt}(\mathrm{nP}) / \mathrm{nC}$ can be seen in Fig. 1a, and is even more apparent in the enlarged diffractograms of Fig $\mathrm{S} 3 \dagger$ of the composites and their respective residue materials (Fig. S3†). This shift has been observed in EXAFS studies of RhPt nanoalloys, ${ }^{39}$ and was explained by a compressing of the metallic lattice due to the simultaneous presence of $\mathrm{Rh}$ and $\mathrm{Pt}$ atoms in the same nanoparticle.

By means of HR-STEM/EDX mappings (Fig. S4 and S5†) it can be seen that the respective metal is present and is detectable only finely distributed on the carbon framework. This may be related to the grafting process of the nanoparticles that is occurring on the carbon framework during the synthesis. The distribution of the nanoparticles was studied in more detail by HR-TEM analysis and it can be seen that the nanoparticles are randomly and finely dispersed on the carbon framework (Fig. S6†). The nanoparticles are crystalline and the metallic nature in case of the $\mathrm{Pt}(\mathrm{nP}) / \mathrm{nC}$ can be once more observed in the diffraction pattern of the nanoparticles (Fig. S7 $\dagger$ ). The size distribution of the nanoparticles is in the range between 2 and $3 \mathrm{~nm}$ and was found to be $2.3 \mathrm{~nm}$ for the $\mathrm{Rh}(\mathrm{nP}) / \mathrm{nC}$ composite and $2.6 \mathrm{~nm}$ for the $\mathrm{Pt}(\mathrm{nP}) / \mathrm{nC}$ based on the analysis of about 20 HR-TEM images for each sample (Fig. S8†).

\section{Electrochemical measurement}

All the electrochemical measurement was performed with a SP-300 bipotentiostat (Biologic Instruments) workstation, using a three-electrode system composed of a saturated calomel electrode (SCE) as reference electrode, a Pt wire as counter electrode and a catalyst-modified glassy carbon electrode (GCE, $3 \mathrm{~mm}$ in diameter, geometric surface area $0.071 \mathrm{~cm}^{2}$ ) as working electrode. The obtained materials were dispersed in a mixed solvent of dimethylformamide (DMF) and $5 \%$ Nafion $(\mathrm{v} / \mathrm{v}=950 / 50)$ under sonication at least half an hour. Then, 30 microliters of the dispersion with a concentration of $1 \mathrm{mg} \mathrm{mL} \mathrm{m}^{-1}$ were drop cast onto a polished GCE surface and dried in air. Commercial $\mathrm{RuO}_{2}$ and $\mathrm{Pt} / \mathrm{C}(20 \mathrm{wt} \%)$ were used as references for the OER and HER catalysis, and were dispersed in the same way. The electrocatalytic performance was evaluated in Ar-saturated 0.1 M KOH solution.

The gas phase quantification was carried out by coupling a Gas Chromatograph (GC) with an electrochemical cell. The gas phase quantification was carried out during the electrolysis of least 1 hour at cathodic potentials, with sampling every 15 minutes. faradaic Efficiency (FE) for the HER was quantified following the procedure previously described by Baltrusaitis et al.: ${ }^{40} \mathrm{FE}(\%)=n F \phi F_{\mathrm{m}} / I$, where $n$ is the number of electrons needed for HER, thus $2 ; F$ is the Faraday constant; $\phi$ is the volume fraction of the gas; $I$ is the current and $F_{\mathrm{m}}$ is the molar Ar gas flow rate.

\section{Results and discussion}

The electrocatalytic activity of $\mathrm{Rh}(\mathrm{nP}) / \mathrm{nC}, \mathrm{RhPt}(\mathrm{nP}) / \mathrm{nC}$ and $\mathrm{Pt}$ $(\mathrm{nP}) / \mathrm{nC}$ for the OER was tested in Ar-saturated $0.1 \mathrm{M} \mathrm{KOH}$ solution. The LSV polarization curves in Fig. 2a showed that it
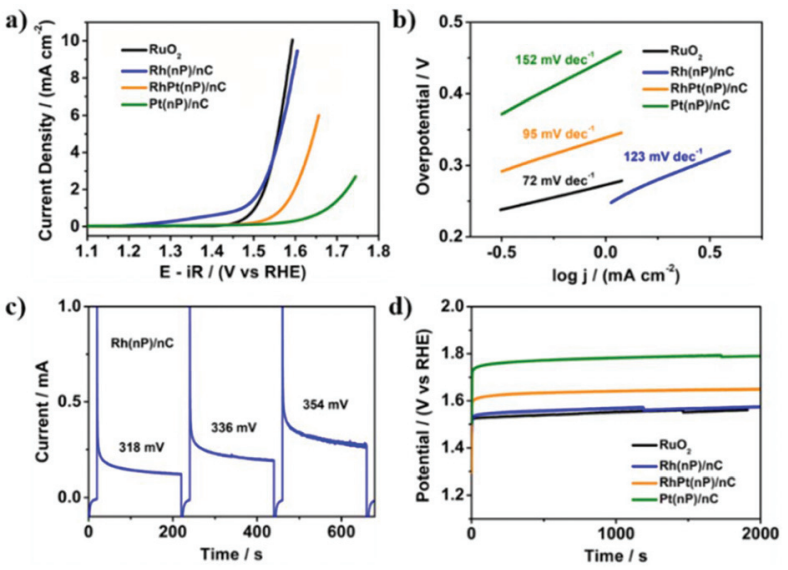

Fig. 2 Electrocatalytic performance for the OER in $0.1 \mathrm{M} \mathrm{KOH}$ solution. (a) LSV polarization curves of commercial $\mathrm{RuO}_{2}, \mathrm{Rh}(\mathrm{nP}) / \mathrm{nC}, \mathrm{RhPt}(\mathrm{nP}) / \mathrm{nC}$ and $\mathrm{Pt}(\mathrm{nP}) / \mathrm{nC}$ at a scan rate of $5 \mathrm{mV} \mathrm{s}^{-1}$. (b) Corresponding Tafel plots. (c) Representative 200 seconds potential steps of $\mathrm{Rh}(\mathrm{nP}) / \mathrm{nC}$ at overpotentials of $0.318 \mathrm{~V}, \quad 0.336 \mathrm{~V}$ and $0.354 \mathrm{~V}$, respectively. (d) Chronopotentiometry curves recorded at a current density of $2 \mathrm{~mA}$ $\mathrm{cm}^{-2}$. The potentials were corrected for iR drop and calibrated to RHE. 
followed an order of $\mathrm{Pt}(\mathrm{nP}) / \mathrm{nC}<\mathrm{RhPt}(\mathrm{nP}) / \mathrm{nC}<\mathrm{Rh}(\mathrm{nP}) / \mathrm{nC}$. In detail, to achieve a current density of $5 \mathrm{~mA} \mathrm{~cm} \mathrm{~cm}^{-2}, \mathrm{Rh}(\mathrm{nP}) / \mathrm{nC}$ needed an overpotential of $333 \mathrm{mV}$, quite similar to that of commercial $\mathrm{RuO}_{2}$, which was $328 \mathrm{mV}$. However, for $\mathrm{RhPt}(\mathrm{nP}) /$ $\mathrm{nC}$ and $\mathrm{Pt}(\mathrm{nP}) / \mathrm{nC}$, much larger overpotentials were required, $414 \mathrm{mV}$ and $555 \mathrm{mV}$, respectively. As shown in Fig. 2b, the Tafel slopes of commercial $\mathrm{RuO}_{2}, \mathrm{Rh}(\mathrm{nP}) / \mathrm{nC}, \mathrm{RhPt}(\mathrm{nP}) / \mathrm{nC}$ and $\mathrm{Pt}(\mathrm{nP}) / \mathrm{nC}$ were $72,123,95$ and $152 \mathrm{mV} \mathrm{dec}^{-1}$. An anodic peak at around $1.4 \mathrm{~V}$ ( $v s$. RHE) of $\mathrm{Rh}(\mathrm{nP}) / \mathrm{nC}$ LSV polarization curve might be attributed to an oxidation process of $\mathrm{Rh}^{3+}$ to $\mathrm{Rh}^{4+}$ before oxygen evolution. ${ }^{41}$

Meanwhile, the electrochemical surface areas (ECSAs) were measured by means of $\mathrm{CV}$ in $0.1 \mathrm{M} \mathrm{KOH}$ solution as shown in Fig. S9. $\uparrow$ By integrating the hydrogen underpotential deposition regions, the ECSAs of $\mathrm{Rh}(\mathrm{nP}) / \mathrm{nC}, \mathrm{RhPt}(\mathrm{nP}) / \mathrm{nC}$ and $\mathrm{Pt}$ $(\mathrm{nP}) / \mathrm{nC}$ were calculated to be $7.7,17.5$ and $22.2 \mathrm{~m}^{2} \mathrm{~g}^{-1}$, respectively, while the commercial $\mathrm{Pt} / \mathrm{C}(20 \%)$ showed a value of $42.8 \mathrm{~m}^{2} \mathrm{~g}^{-1}$.

Meanwhile, a sequence of potential steps (200 seconds for each) under different overpotentials were carried out in order to achieve TOF for the OER (see Fig. 2c). Based on the charges transferred during potential steps, the TOF values of $\mathrm{Rh}(\mathrm{nP}) /$ $\mathrm{nC}$ were $0.013 \mathrm{~s}^{-1}, 0.019 \mathrm{~s}^{-1}$ and $0.026 \mathrm{~s}^{-1}$ at overpotentials of $318 \mathrm{mV}, 336 \mathrm{mV}$ and $354 \mathrm{mV}$, respectively, as shown in Fig. S10. $\dagger$ Here, we assumed that every single metal atom was catalytically active for the OER. Thus, the observed values are the lower limits of TOF, because likely not all particles are accessible. When compared with literatures, $\mathrm{Rh}(\mathrm{nP}) / \mathrm{nC}$ showed a high level of TOF. For example, at an overpotential of $350 \mathrm{mV}$, it is 2.5 times larger than that of the commercial $\mathrm{RuO}_{2}$ (see Fig. S11†).

Besides, the durability of $\mathrm{RuO}_{2}, \mathrm{Rh}(\mathrm{nP}) / \mathrm{nC}, \mathrm{RhPt}(\mathrm{nP}) / \mathrm{nC}$ and $\mathrm{Pt}(\mathrm{nP}) / \mathrm{nC}$ for the OER was investigated by conducting chronopotentiometry measurement at a current density of $2 \mathrm{~mA} \mathrm{~cm} \mathrm{~cm}^{-2}$ as shown in Fig. 2d. After 2000 seconds only slight increase of potentials was observed indicating that the prepared nanocomposites were quite stable for the catalytic OER in alkaline media. This interpretation can be corroborated by SEM/EDX measurements of the surfaces before and after electrolysis, where the rhodium atomic content seems unchanged. Although the surface gets rougher and porous pointing towards limits in the preparation technique of the electrodes (Fig. S12†), the $\mathrm{CV}$ curves of $\mathrm{Rh}(\mathrm{nP}) / \mathrm{nC}$ before and after the OER durability test (Fig. S13†) did not change much, which means that the value of the ECSA of $\mathrm{Rh}(\mathrm{nP}) / \mathrm{nC}$ remained almost constant during catalysis. This confirmed that $\mathrm{Rh}(\mathrm{nP}) /$ $\mathrm{nC}$ is stable for the OER in alkaline media. We compared the OER performance of $\mathrm{Rh}(\mathrm{nP}) / \mathrm{nC}$ in alkaline medium with previous works and it showed that $\mathrm{Rh}(\mathrm{nP}) / \mathrm{nC}$ displayed relatively lower overpotential at a current density of $10 \mathrm{~mA} \mathrm{~cm}{ }^{-2}$ (see Table ST2†).

On the other side, the electrocatalytic activity of $\mathrm{Rh}(\mathrm{nP}) / \mathrm{nC}$, $\mathrm{RhPt}(\mathrm{nP}) / \mathrm{nC}$ and $\mathrm{Pt}(\mathrm{nP}) / \mathrm{nC}$ for the HER was evaluated in $\mathrm{Ar}-$ saturated 0.1 M KOH solution. The HER polarization curves were recorded at a scan rate of $5 \mathrm{mV} \mathrm{s}^{-1}$. As shown in Fig. 3a, at a current density of $2 \mathrm{~mA} \mathrm{~cm}{ }^{-2}$, overpotentials of the $\mathrm{Rh}$
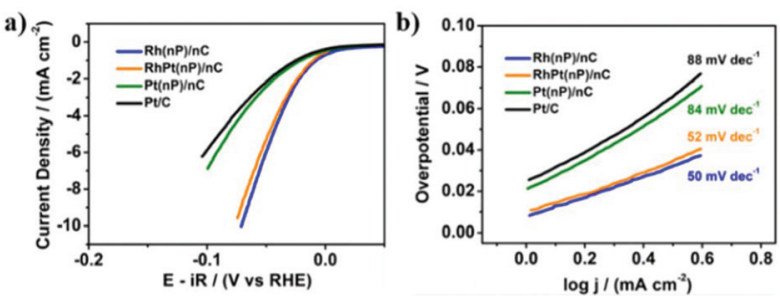

Fig. 3 HER performance of $\mathrm{Rh}(\mathrm{nP}) / \mathrm{nC}, \mathrm{RhPt}(\mathrm{nP}) / \mathrm{nC}, \mathrm{Pt}(\mathrm{nP}) / \mathrm{nC}$ and commercial $\mathrm{Pt} / \mathrm{C}$ in $0.1 \mathrm{M} \mathrm{KOH}$ solution. (a) LSV polarization curves at a scan rate $5 \mathrm{mV} \mathrm{s}^{-1}$. (b) Corresponding Tafel plots. The potentials were corrected for iR drop and calibrated to RHE.

$(\mathrm{nP}) / \mathrm{nC}, \operatorname{RhPt}(\mathrm{nP}) / \mathrm{nC}$ and $\mathrm{Pt}(\mathrm{nP}) / \mathrm{nC}$ are 44,48 and $82 \mathrm{mV}$, respectively, better than commercial $\mathrm{Pt} / \mathrm{C}$ with a higher overpotential of $90 \mathrm{mV}$, though in acidic media commercial $\mathrm{Pt} / \mathrm{C}$ behaves better than $\mathrm{Rh}(\mathrm{nP}) / \mathrm{nC}$ (see Fig. S14 $\dagger$ ). The good performance of all here discussed composite materials can be traced back to the small size of the nanoparticles and the large amount of edges, shown to be beneficial for electrocatalytic performances. ${ }^{42}$ Noteworthy is the increased performance of the $\mathrm{RhPt}(\mathrm{nP}) / \mathrm{nC}$ over its $\mathrm{Pt}(\mathrm{nP}) / \mathrm{nC}$ counterpart for the HER. We attribute this fact to the nanoalloy structure of RhPt(nP)/ nC.

In order to study the HER reaction kinetics, Tafel slopes were calculated based on LSV polarization curves. We can see from Fig. $3 \mathrm{~b}$ that $\mathrm{Rh}(\mathrm{nP}) / \mathrm{nC}$, $\mathrm{RhPt}(\mathrm{nP}) / \mathrm{nC}$ and $\mathrm{Pt}(\mathrm{nP}) / \mathrm{nC}$ displayed low Tafel slopes, which were 50,52 and $84 \mathrm{mV} \mathrm{dec}^{-1}$, respectively, while that of commercial Pt/C was $88 \mathrm{mV} \mathrm{dec}^{-1}$. It is known that lower Tafel slope means more rapid raise of product generation as overpotential increases. Therefore, the prepared carbon supported noble nanoparticles are supposed to have faster reaction kinetics than commercial $\mathrm{Pt} / \mathrm{C}$ for the HER. Finally, faradaic Efficiency (FE) for the HER was quantified following the procedure previously described. ${ }^{43}$ After one hour of electrolysis, both electrocatalysts of $\mathrm{Rh}(\mathrm{nP}) / \mathrm{nC}$ and $\mathrm{Pt}$ $(\mathrm{nP}) / \mathrm{nC}$ reached the $100 \%$ of $\mathrm{FE}$.

We have physically mixed $\mathrm{Rh}(\mathrm{nP}) / \mathrm{nC}$ and $\mathrm{Pt}(\mathrm{nP}) / \mathrm{nC}$ with a ratio of $1: 1$ and investigated its electrocatalytic performances for the OER and HER. As can be seen from Fig. S15, $\dagger$ Rh-Pt mixture showed lower current densities at same overpotentials and larger Tafel slopes than the prepared $\operatorname{RhPt}(\mathrm{nP}) / \mathrm{nC}$. This in some way confirmed that there might be a combination between Rh and Pt inside RhPt(nP)/nC sample, which contributes to its superior activities. When comparing the HER activity of $\mathrm{Rh}(\mathrm{nP}) / \mathrm{nC}$ with other reported catalysts (Table ST3 $\dagger$ ), we can see that $\mathrm{Rh}(\mathrm{nP}) / \mathrm{nC}$ is more efficient among them considering its low overpotential and Tafel slope. For practical use, a two-electrode electrolyzer using $\mathrm{Rh}(\mathrm{nP}) / \mathrm{nC}$ (loaded on two glassy carbon electrodes) as both anode and cathode was built for water splitting in $0.1 \mathrm{M} \mathrm{KOH}$. As shown in Fig. S16, $\uparrow$ a voltage of $1.68 \mathrm{~V}$ for $\mathrm{Rh}(\mathrm{nP}) / \mathrm{nC}|| \mathrm{Rh}(\mathrm{nP}) / \mathrm{nC}$ couple was required to achieve a current density of $10 \mathrm{~mA}$ $\mathrm{cm}^{-2}$, which corresponded to the potential difference between the HER and OER needed in the half cells when using $\mathrm{Rh}(\mathrm{nP}) /$ $\mathrm{nC}$ as catalysts. 


\section{Conclusions}

In summary, well-dispersed noble metal nanoparticles (Rh and $\mathrm{Pt}$ ) and mixed metal nanoparticles (RhPt) with an average size of about $2.5 \mathrm{~nm}$ on carbon were synthesized. Their catalytic activity for the HER and OER was investigated in alkaline media. It was found that all the prepared nanocomposites displayed superior HER performance than commercial Pt/C. Our results emphasis that the $\mathrm{Rh}(\mathrm{nP}) / \mathrm{nC}$ displays the lowest overpotential and smallest Tafel slope, and thus it is an excellent catalyst for this reaction. Furthermore, $\mathrm{Rh}(\mathrm{nP}) / \mathrm{nC}$ also exhibited a comparable activity for the OER to the commercial $\mathrm{RuO}_{2}$, which is one of the best catalytic materials known for this reaction. The superior performance of this catalyst can also be preserved when the active materials are mixed, either chemically or physically, with the respective platinum analogue. This is an important asset in a commercial context.

The effective catalytic HER and OER performance can be attributed to a good combination between carbon support and nanoparticles The obtained carbon supported noble nanoparticles are excellent and promising electrocatalysts for alkaline water splitting, and further improvements on the preparation of the electrode will allow to exploit the full potential of these catalysts.

\section{Conflicts of interest}

There are no conflicts to declare.

\section{Acknowledgements}

F. H. and A. P. thank the French ANR (EdgeFiller project). F. H. thanks CNRS (Momentum grant). We thank Ahmed Bentaleb for XRD measurements and $M$. Gayot and C. Labrugère Sarroste, PLACAMAT, for HR-TEM and XPS measurements respectively. M. L. thanks Chinese Scholarship Council No. 201709370059 for funding support. M. L., M. M., G. V. and F. P. thank the Italian Ministero dell'Istruzione, Università e Ricerca, University of Bologna.

\section{References}

1 J. Wang, F. Xu, H. Jin, Y. Chen and Y. Wang, Adv. Mater., 2017, 29, 1605838.

2 M. E. G. Lyons and S. Floquet, Phys. Chem. Chem. Phys., 2011, 13, 5314-5335.

3 C. Wei, R. R. Rao, J. Peng, B. Huang, I. E. L. Stephens, M. Risch, Z. J. Xu and Y. Shao-Horn, Adv. Mater., 2019, 31, 1806296.

4 B. You and Y. Sun, Acc. Chem. Res., 2018, 51, 1571-1580.

5 Y. Jiao, Y. Zheng, M. Jaroniec and S. Z. Qiao, Chem. Soc. Rev., 2015, 44, 2060-2086.

6 W. Sheng, H. A. Gasteiger and Y. Shao-Horn, J. Electrochem. Soc., 2010, 157, B1529-B1536.
7 A. C. Garcia and M. T. M. Koper, ACS Catal., 2018, 8, 93599363.

8 N.-T. Suen, S.-F. Hung, Q. Quan, N. Zhang, Y.-J. Xu and H. M. Chen, Chem. Soc. Rev., 2017, 46, 337-365.

9 G. Valenti, A. Boni, M. Melchionna, M. Cargnello, L. Nasi, G. Bertoni, R. J. Gorte, M. Marcaccio, S. Rapino, M. Bonchio, P. Fornasiero, M. Prato and F. Paolucci, Nat. Commun., 2016, 7, 13549.

10 H. Duan, D. Li, Y. Tang, Y. He, S. Ji, R. Wang, H. Lv, P. P. Lopes, A. P. Paulikas, H. Li, S. X. Mao, C. Wang, N. M. Markovic, J. Li, V. R. Stamenkovic and Y. Li, J. Am. Chem. Soc., 2017, 139, 5494-5502.

11 M. B. Chambers, X. Wang, N. Elgrishi, C. H. Hendon, A. Walsh, J. Bonnefoy, J. Canivet, E. A. Quadrelli, D. Farrusseng, C. Mellot-Draznieks and M. Fontecave, ChemSusChem, 2015, 8, 603-608.

12 L. Zhu, H. Lin, Y. Li, F. Liao, Y. Lifshitz, M. Sheng, S.-T. Lee and M. Shao, Nat. Commun., 2016, 7, 12272.

13 D. A. J. M. Ligthart, R. A. van Santen and E. J. M. Hensen, Angew. Chem., Int. Ed., 2011, 50, 5306-5310.

14 V. Rico-Pérez, S. Parres-Esclapez, M. J. Illán-Gómez, C. S.-M. de Lecea and A. Bueno-López, Appl. Catal., B, 2011, 107, 18-25.

15 N. Zhang, Q. Shao, Y. Pi, J. Guo and X. Huang, Chem. Mater., 2017, 29, 5009-5015.

16 J. Bai, S.-H. Han, R.-L. Peng, J.-H. Zeng, J.-X. Jiang and Y. Chen, ACS Appl. Mater. Interfaces, 2017, 9, 17195-17200.

17 J. Zhu, L. Hu, P. Zhao, L. Y. S. Lee and K.-Y. Wong, Chem. Rev., 2020, 120, 851-918.

18 Y. Zhu, H. C. Chen, C. S. Hsu, T. S. Lin, C. J. Chang, S. C. Chang, L. D. Tsai and H. M. Chen, ACS Energy Lett., 2019, 4, 987-994.

19 S. F. Hung, Y. Chan, C. C. Chang, M. K. Tsai, Y. F. Liao, N. Hiraoka, C. S. Hsu and H. M. Chen, J. Am. Chem. Soc., 2018, 140, 17263-17270.

20 Y. Zhu, J. Wang, H. Chu, Y. C. Chu and H. M. Chen, ACS Energy Lett., 2020, 5, 1281-1291.

21 U. Narula, C. M. Tan and E. S. Tok, Adv. Mater. Interfaces, 2018, 5, 1800270.

22 S. F. Hung, Y. Zhu, G. Q. Tzeng, H. C. Chen, C. S. Hsu, Y. F. Liao, H. Ishii, N. Hiraoka and H. M. Chen, ACS Energy Lett., 2019, 4, 2813-2820.

23 H. C. Chen, T. L. Chen, S. C. Lin, C. S. Hsu, T. S. Chan, M. Y. Liao and H. M. Chen, ChemCatChem, 2020, 12, 19261933.

24 Z. W. Seh, J. Kibsgaard, C. F. Dickens, I. Chorkendorff, J. K. Nørskov and T. F. Jaramillo, Science, 2017, 355, eaad4998.

25 L. Liu and A. Corma, Chem. Rev., 2018, 118, 4981-5079.

26 N. Cheng, S. Stambula, D. Wang, M. N. Banis, J. Liu, A. Riese, B. Xiao, R. Li, T.-K. Sham, L.-M. Liu, G. A. Botton and X. Sun, Nat. Commun., 2016, 7, 13638.

27 Q. Wang, M. Ming, S. Niu, Y. Zhang, G. Fan and J.-S. Hu, Adv. Energy Mater., 2018, 8, 1801698.

28 W. Zhang, X. Zhang, L. Chen, J. Dai, Y. Ding, L. Ji, J. Zhao, M. Yan, F. Yang, C.-R. Chang and S. Guo, ACS Catal., 2018, 8, 8092-8099. 
29 C. Vallés, C. Drummond, H. Saadaoui, C. A. Furtado, M. He, O. Roubeau, L. Ortolani, M. Monthioux and A. Pénicaud, J. Am. Chem. Soc., 2008, 130, 15802-15804.

30 F. Hof and A. Pénicaud, Chem. - Eur. J., 2018, 24, 1624616250.

31 F. Hof, A. Boni, G. Valenti, K. Huang, F. Paolucci and A. Pénicaud, Chem. - Eur. J., 2017, 23, 15283-15288.

32 F. Hof, M. Liu, G. Valenti, E. Picheau, F. Paolucci and A. Pénicaud, J. Phys. Chem. C, 2019, 123, 2077420780.

33 F. Hof, K. Kampioti, K. Huang, C. Jaillet, A. Derré, P. Poulin, H. Yusof, T. White, K. Koziol, C. Paukner and A. Pénicaud, Carbon, 2017, 111, 142-149.

34 L. Gustavo Cançado, M. Gomes da Silva, E. H. Martins Ferreira, F. Hof, K. Kampioti, K. Huang, A. Pénicaud, C. Alberto Achete, R. B. Capaz and A. Jorio, 2D Mater., 2017, 4, 025039.

35 R. Subbaraman, D. Tripkovic, D. Strmcnik, K.-C. Chang, M. Uchimura, A. P. Paulikas, V. Stamenkovic and N. M. Markovic, Science, 2011, 334, 1256-1260.
36 J. Greeley, J. K. Nørskov, L. A. Kibler, A. M. El-Aziz and D. M. Kolb, ChemPhysChem, 2006, 7, 1032-1035.

37 J. Chattopadhyay, S. Chakraborty, A. Mukherjee, R. Wang, P. S. Engel and W. E. Billups, J. Phys. Chem. C, 2007, 111, 17928-17932.

38 D. Fino, S. Bensaid, M. Piumetti and N. Russo, Appl. Catal., A, 2016, 509, 75-96.

39 T. J. P. Hersbach, R. Kortlever, M. Lehtimäki, P. Krtil and M. T. M. Koper, Phys. Chem. Chem. Phys., 2017, 19, 1030110308.

40 R. Kas, R. Kortlever, A. Milbrat, M. T. M. Koper, G. Mul and J. Baltrusaitis, Phys. Chem. Chem. Phys., 2014, 16, 1219412201.

41 J. Juodkazytė and K. Juodkazis, Electroanal. Int. J. Devoted Fundam. Pract. Asp. Electroanal., 2004, 16, 1622-1627.

42 C. M. Zalitis, A. R. Kucernak, J. Sharman and E. Wright, J. Mater. Chem. A, 2017, 5, 23328-23338.

43 E. Verlato, S. Barison, Y. Einaga, S. Fasolin, M. Musiani, L. Nasi, K. Natsui, F. Paolucci and G. Valenti, J. Mater. Chem. A, 2019, 7, 17896-17905. 